\title{
Understanding Curricular Approaches to Communication as a Global Com- petency: An Interdisciplinary Study of the Teaching and Learning of Com- munication
}

\section{Dr. Christina Kay White, Massachusetts Institute of Technology}

Dr. Christina White is currently a postdoctoral engineering education research associate with SingaporeMIT Alliance for Research and Technology (SMART) Innovation Centre. She completed her Doctoral degree from Teachers College, Columbia University where she studied engineering education. She is the founding director of the National Academy of Engineering Longhorn Grand Challenges Scholars \& K12 Partners Program at The University of Texas at Austin. Dr. White is also the director of an outreach program called Design, Technology, \& Engineering for All Children (DTEACh) which has reached more than 1000 teachers and 85,000 students. She is the lead inventor on a patent for assistive technology. Her current research includes global competencies, innovative design-based pedagogy, humanitarian engineering, and ways to attract and retain traditionally underrepresented groups in engineering education.

Dr. Lori Breslow, Massachusetts Institute of Technology

Dr. Daniel E. Hastings, Massachusetts Institute of Technology 


\section{Understanding Curricular Approaches to Communication as a Global Competency: \\ A Study of the Teaching and Learning of Communication Skills at Three Universities}

\section{Introduction}

As society grows more global and interconnected, the challenges that must be addressed by the next generation of engineers are becoming more complex [1-2]. Engineers need deep technical expertise, of course, but they also need what have typically been called 21 st-century skills, for example, critical thinking, problem solving, teamwork, and communication. Technical knowledge and "soft" skills are complementary, and both are necessary if engineers are to help solve the most serious problems our societies face [3-4]. This call for engineering education to position itself so students can meet modern challenges was laid out by the leaders of the National Academy of Engineering (NAE) in their influential reports, The Engineer of 2020 [5-6]. There is now a need to reflect on how engineering education has positively changed in the decade since those reports, and to consider what still needs to be tackled.

Our research aligns with one of the key recommendations of The Engineer of 2020: to develop engineers whose communication skills will allow them to become successful professionals and, who, in turn, will drive technological and social change. Specifically, we examine how engineering schools are helping students develop four key communication competencies: writing, creating and delivering presentations, developing and employing visual literacy skills, and participating in teams. The Organization for Economic Co-operation and Development's (OECD) Definition and Selection of Competencies (DeSeCo) Project describes "competency" as:

...more than just knowledge and skills. It involves the ability to meet complex demands, by drawing on and mobilizing psychosocial resources (including skills and attitudes) in a particular context. For example, the ability to communicate effectively is a competency that may draw on an individual's knowledge of language, practical IT skills and attitudes towards those with whom he or she is communicating [7].

Engineering schools and departments need to produce diverse leaders for the global workforce and in society. But in order to do that, engineers need strong communication skills that will allow them to interact with a wide-ranging audience, including policy makers, community leaders, and the general public - all of whom do not necessarily have a strong understanding of science and technology.

In this paper, we describe preliminary results of a pilot survey we administered at three universities asking students to report on their levels of self-efficacy for four communication competencies: oral presentation skills, 2) written communication, 3) visual literacy skills, and 4) teamwork. Our study sites include two Asian universities and one university in the U.S. (We will add another U.S. university as the fourth study site; however, at the time the pilot survey was administered, this institution was awaiting IRB approval for the study.) We recognize that 
communication encompasses a variety of activities undertaken by engineers, including interacting in meetings, talking on the telephone, writing e-mails, creating computer-aided drawings, or producing visual models [8], but we focus on these four skills because we believe they are the foundation of the communication competencies that engineering graduates need to master. We report on commonalities in students' self-efficacy for these skills, what they perceive their weaknesses to be, and their goals for strengthening their abilities.

These findings will feed into a larger study in which we examine two curricular approaches in which these communication skills are taught: an analysis-centric approach and a design-centric approach. We do not claim that each institution can be placed into a silo of one particular curricular approach, but instead each can be benchmarked on a continuum of pedagogical practices. However, we believe that where these institutions sit on the analysis-design spectrum varies enough that we will see interesting differences in how communication skills are taught, and the impact of those practices on student learning. We believe this attention to understanding the learning ecology of each institution is critical because research clearly demonstrates that the development of communication skills relies heavily on situated learning, in which, for example, the context surrounding an assignment can be as important as the assignment itself [9-10].

Eventually, we will use a mix of quantitative and qualitative research methodologies in the study. In addition to the student survey of self-efficacy, which will be given both to first-year and graduating students, we will use four other data collection techniques: (1) an inventory of the types and frequency of communication experiences and assignments given at each institution drawn from course syllabi; (2) a faculty survey to gauge instructors' confidence in their ability to teach communication skills and the value they place on communication; (3) student and faculty focus groups to complement the surveys; and (4) classroom observations.

\section{Methodology}

The development of the survey began with a review of the research on teaching engineering students communication skills. We also drew on the classic literature on self-efficacy.

According to work most notably by Bandura [11-12], success is not only based on the possession of necessary skills, it also requires the confidence to use these skills effectively. Those individuals who develop a strong sense of self-efficacy are well equipped to educate themselves when they have to rely on their own initiative. One of the goals of teaching communication skills is to develop students who feel competent and confident in the use of those skills [13]. Our student survey is designed to measure the extent to which students at our study sites have developed a sense of self-efficacy for communication.

The survey lists the sub-skills we have identified, both from the literature and from experience in teaching communication skills, that student must master in order to successfully create and deliver oral presentations, write, develop and use visual literacy skills, and participate in teamwork. For example, for oral presentations, we asked students about their confidence in their ability to "identify the characteristics of the audience to whom I am speaking," and for writing, we asked them about their confidence in their ability to "meet the audience's needs and my own purposes." In all, we inquired about the students' confidence in 44 sub-skills that composed the four major categories of communication abilities we are exploring. Additionally, we asked three 
open-ended questions: What are your greatest strengths in communication? If you could improve in communication, how would you like to improve? What kinds of skills are valuable for an engineer? This mixed method of collecting quantitative and qualitative data provided a comprehensive understanding of students' perspectives on communication.

For the next step in the pilot, members of the research team met with a total of twenty student volunteers from the participating universities, ten students from the U.S. university and ten from the universities in Asia so we could observe students actually taking the survey and discuss it with them. The student volunteers were diverse in multiple ways, including engineering discipline, ethnicity, gender, first language/native tongue, and academic performance. They had the opportunity to use their own device or one of the computers at the research site to take the online survey, and they also had a hard copy of the survey upon which to take notes.

After we explained the study to the students using a script so there would be a common protocol at each institution, the students went through the survey question by question. They were asked to read each question out loud, tell us what they thought the question was asking, and then give their answer. We checked to see if the wording of the questions was clear or if any of the individual words or phrases was confusing. The students were also asked to describe their feelings about the options response scale and if it made sense. We wanted to know their opinion about the length of the survey, including if they would be motivated to finish it, and if they felt it was too long, to indicate at what point they began to feel that way. At the end of the session, students were prompted to provide their perspectives on the layout of the survey, and they were asked if they had any additional feedback that might improve the survey. The research team compiled notes about the students' responses and made modifications to the survey based on the insights from this first phase.

In the second phase of the pilot study, the survey was administered to first-year engineering students at the three universities. A total of 523 students responded, including a diverse representation in terms of engineering discipline, ethnicity, gender, and first language/native tongue.

We initially analyzed the data to compare means between universities. To do this, we needed to determine if there were statistically significant differences in the means of the data from each school. Our data sets are independent and are unequal population sizes so we first used an F-test to determine if the variances were equal or unequal. Then, we ran a two-tailed T-test to compare the means to determine those categories that had a low P-value $(\mathrm{p}>.05)$, indicating that there was a significant difference between the means, thus between the schools. At this initial pilot stage, we are not seeing significant differences between the schools, but an interesting finding from the data is that we are able to identify common areas where students feel the most and least amounts of self-efficacy in communication, which we describe in the next section. We will continue to employ several methods of data analysis, including means comparisons, in the larger study and we will report the findings. 


\section{Findings}

We analyze the data from the first student survey to indicate the level of self-efficacy for each communication skill. We include quantitative results and qualitative trends from the survey to report similar findings for those communication sub-skills which students report the most and least confidence. The data in the first four tables below indicate the highest and lowest mean scores for students' perceptions of self-efficacy for sub-skills that contribute to creating and delivering presentations (Table 1), writing (Table 2), developing and using visual literacy (Table 3), and working in teams (Table 4) at all three universities, identified as University A, B, and C. In each of the tables, cells in blue indicate the three highest means in confidence in specific subskills that contribute to one of the four communication competencies, and the cells in tan indicate the three lowest means in confidence for specific sub-skills. We have only included a sub-skill if students in at least two of the three universities reported they were either most confident or least confident in it.

There was most consistency in the results for teamwork: that is, students at all three universities report they are most confident in the same two sub-skills (listen respectfully and interact to find solutions to problems) and least confident in the same two sub-skills (clarify the source of problems and identify cross-cultural communication difference). Oral communication had the next highest number of similarities in means. At all three universities, students expressed the most confidence in two sub-skills (develop a presentation that shares my purpose and provide evidence to support the main idea) and not very much confidence in two sub-skills (not using fillers like "umm" and gesturing). Results in the other sub-skills that compose our four communication competencies were only consistent across two universities and often those two universities were not the same.

Table 1. Highest and Lowest Mean Scores for Students' Self-Efficacy in Oral Presentation Skills

\begin{tabular}{|l|l|c|c|c|}
\hline Oral & \multicolumn{1}{|c|}{ A } & B & & \\
\hline High & \multicolumn{1}{|c|}{ C } & \\
\hline & $\begin{array}{l}\text { develop a presentation that effectively shares the purpose of my } \\
\text { message. }\end{array}$ & 8.02 & 7.58 & 8.4 \\
\hline & $\begin{array}{l}\text { provide evidence that supports the main idea, argument, or } \\
\text { recommendation. }\end{array}$ & 8.14 & 7.78 & 8.77 \\
\hline Low & & & & \\
\hline & speak with few fillers such as ummm & 6.33 & 6.31 & 6.65 \\
\hline & use gestures effectively. & 6.6 & 6.89 & 7.04 \\
\hline
\end{tabular}


Table 2. Highest and Lowest Mean Scores for Students' Self-Efficacy in Written Communication

\begin{tabular}{|l|l|c|c|c|}
\hline Written & \multicolumn{1}{|c|}{ A } & B & C \\
\hline High & \multicolumn{1}{|c|}{} & & \\
\hline & $\begin{array}{l}\text { lunctuate sentences correctly (for example, quotation marks, commas, } \\
\text { and periods). }\end{array}$ & 7.92 & 8.5 & 9.7 \\
\hline & use grammar correctly. & 7.9 & 8.16 & 9.35 \\
\hline & $\begin{array}{l}\text { Use formatting (for example, subheads, bulleted lists) effectively to } \\
\text { highlight important ideas or to help the audience skim the document. }\end{array}$ & 8.26 & 7.76 & 8.2 \\
\hline & $\begin{array}{l}\text { provide evidence that supports the main idea, argument, or } \\
\text { recommendation. }\end{array}$ & 8 & 7.58 & 8.63 \\
\hline Low & $\begin{array}{l}\mid \\
\text { loate a strong introduction (for example, provide an overview of the } \\
\text { document). }\end{array}$ & 7.26 & 7.37 & 7.99 \\
\hline & write concise sentences. & 7.59 & 7.38 & 8.18 \\
\hline & identify the audience for whom I am writing. & 7.18 & 7.37 & 8.35 \\
\hline
\end{tabular}

Table 3. Highest and Lowest Mean Scores for Students' Self-Efficacy in Visual Literacy

\begin{tabular}{|c|c|c|c|c|}
\hline Visual & & A & B & $\mathbf{C}$ \\
\hline \multicolumn{5}{|l|}{ High } \\
\hline & $\begin{array}{l}\text { edit images, as necessary, for layout and display (for example, crop } \\
\text { photos). }\end{array}$ & 8.11 & 7.94 & 9.15 \\
\hline & $\begin{array}{l}\text { create visual media that represents data (for example, charts, graphs, } \\
\text { and word clouds). }\end{array}$ & 8.11 & 7.52 & 8.77 \\
\hline & $\begin{array}{l}\text { use titles or captions with visual media to enhance the audiences' } \\
\text { understanding of the message. }\end{array}$ & 8 & 7.67 & 8.53 \\
\hline \multicolumn{5}{|l|}{ Low } \\
\hline & $\begin{array}{l}\text { include source information in citations and statements of credit, as } \\
\text { necessary. }\end{array}$ & 7.6 & 7.27 & 7.91 \\
\hline & $\begin{array}{l}\text { create visual media that communicate concepts, narratives, or } \\
\text { arguments (for example, concept maps, storyboards, and posters). }\end{array}$ & 7.83 & 7.21 & 7.86 \\
\hline & identify if there are legal restrictions on the use of an image. & 6.69 & 6.27 & 6.58 \\
\hline
\end{tabular}

Table 4. Highest and Lowest Mean Scores for Students' Self-Efficacy in Teamwork

\begin{tabular}{|c|c|c|c|c|}
\hline Team & & A & B & C \\
\hline \multicolumn{5}{|l|}{ High } \\
\hline & listen to team members' ideas and points of view respectfully. & 8.72 & 8.63 & 9.49 \\
\hline & interact with team members to find solutions to problems. & 8.34 & 8.06 & 9 \\
\hline & provide feedback to other team members respectfully. & 8.31 & 8.25 & 8.96 \\
\hline \multicolumn{5}{|c|}{ 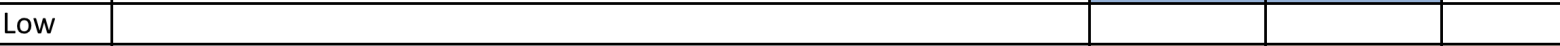 } \\
\hline & clarify the source of problems when they arise. & 7.75 & 7.69 & 8.13 \\
\hline & $\begin{array}{l}\text { identify verbal and non-verbal behaviours that may be due to different } \\
\text { cultural norms of team members (for example, hand gestures, slang } \\
\text { words, eye contact). }\end{array}$ & 7.56 & 7.56 & 7.82 \\
\hline & express my ideas clearly to other team members. & 7.66 & 7.53 & 8.76 \\
\hline
\end{tabular}

As noted above, we initially analyzed the data to compare means between universities, but, at this initial stage of work, we could not find significant differences among the schools perhaps because of the small sample size. But we began to look more closely at the categories of subskills we asked students to report on. Developing expertise in any field of endeavor requires that students master both basic, fundamental skills (think of compulsory numbers in figure skating) and more sophisticated capabilities that require synthesis, creativity, or innovation (the ice 
dancing routines). The educational psychologist David Ausubel, for example, proposed a continuum of cognitive tasks from rote memorization to meaningful learning in the 1960s [14]. We suggest a classification scheme for expertise in communication that moves from mechanical (e.g., use punctuation correctly or speak with few fillers such as "umm") to strategic/critical (e.g., provide evidence in an oral presentation that supports the main idea, argument or recommendation or write to meet the audience's needs and my own purposes). We have done an initial classification of the sub-skills in our survey, and Table 5 places those sub-skills in speaking, writing, and developing and using visual literacy that students most consistently report high or low confidence in. We could not classify teamwork skills quite as neatly, however, as we discuss below.

\section{Classification Scheme for Three Communication Competencies by Sub-Skills}

\begin{tabular}{|c|c|c|c|}
\hline \multirow{3}{*}{ SPEAKING } & \multicolumn{2}{|l|}{ MECHANICAL } & STRATEGIC/CRITICAL \\
\hline & $\begin{array}{l}\text { Speak with few fillers such as } \\
\text { "umm"* }\end{array}$ & & $\begin{array}{l}\text { Develop a presentation that effectively } \\
\text { shares the purpose of my message } e^{*}\end{array}$ \\
\hline & Use gestures effectively* & & $\begin{array}{l}\text { Provide evidence that supports main } \\
\text { idea, argument, or recommendation }{ }^{*}\end{array}$ \\
\hline \multirow{4}{*}{ WRITING } & Punctuate sentences correctly & & \multirow{2}{*}{$\begin{array}{l}\text { Provide evidence that supports main } \\
\text { idea, argument, or recommendation }\end{array}$} \\
\hline & Use grammar correctly & & \\
\hline & Use formatting effectively & & Create a strong introduction ${ }^{*}$ \\
\hline & Write concise sentences & & $\begin{array}{l}\text { Identify the audience for whom I } \\
\text { am writing }\end{array}$ \\
\hline \multirow{3}{*}{$\begin{array}{l}\text { VISUAL } \\
\text { LITERACY }\end{array}$} & $\begin{array}{l}\text { Use titles or captions to } \\
\text { enhance understanding }\end{array}$ & $\begin{array}{l}\text { Edit images for layout, and } \\
\text { display (e.g. crop photos) }\end{array}$ & \multirow[t]{3}{*}{$\begin{array}{l}\text { Create visual media that communicate } \\
\text { concepts, narratives, \& arguments (e.g., } \\
\text { concept maps, story boards) }\end{array}$} \\
\hline & $\begin{array}{l}\text { Include source informa- } \\
\text { tion in citations \& } \\
\text { statements of credit* }\end{array}$ & $\begin{array}{l}\text { Create visual media that } \\
\text { represents data (e.g., charts } \\
\& \text { graphs) }\end{array}$ & \\
\hline & $\begin{array}{l}\text { Identify legal restrictions } \\
\text { on use of image }\end{array}$ & & \\
\hline
\end{tabular}

Table 5: Communication sub-skills categorized along a continuum from "mechanical" to "strategic/critical"; within blue boxes are sub-skills for which students reported high levels of confidence; within tan boxes are sub-skills for which students reported low levels of confidence; asterisk $\left({ }^{*}\right)$ indicates agreement among students at all three schools.

If we only take into account the sub-skills for which students reported high/low confidence uniformly at all three universities, several interesting — although preliminary —observations can be made. For example, all the students report high levels of self-confidence in the mechanical aspects of writing (e.g., using punctuation and grammar correctly or using formatting effectively), but they are not as confident in the mechanics associated with presenting (e.g., speaking with few fillers like "umm" and using gestures effectively) whether or not English is their first language. (It should be noted that the students at the Asian universities are expected to speak and write English fluently.) Students are also not confident in some of the mechanics associated with visual literacy (e.g., citing sources of images or identifying legal restrictions on 
their use) although they were confident they could create effective captions for illustrations, charts, and graphs.

If we look at the strategic/critical end of the continuum for speaking and writing, students at all three universities report they can use evidence to support an idea, argument, or recommendation, but they are less confident in using visual media to communicate an argument if it is conceptual; they believe, however, they can use visual media to represent data. We find it interesting that students have confidence in their ability to "share the purpose of my message" when they are giving a presentation across all universities, but they are less sure of their ability to identify their audience for a written document.

In regard to teamwork, it is hard to classify any of the eight items on our survey as mechanical because they all ask students to report on rich interpersonal skills such as listening, encouraging, and problem solving. Students at all three universities told us they felt confident in their ability to listen to team members respectfully, and students at two of the three universities said they were ably to provide feedback to other members of a team in the same way. (The mean for the third university for that item was actually quite high although not one of the three highest items on that scale.) There was a similar consistency among the items that students at all three universities were less confident in: they felt they had trouble in defining the source of a problem if one occurred, and they were not very sure of their ability to identify cross-cultural communication behaviors, whether in spoken language or non-verbal behavior.

The qualitative data complement the quantitative results of the survey. As noted above, students were prompted to respond to three open-ended questions at the end of the survey. We asked them to provide their perspectives on their communication strengths, how they wanted to improve their communication, and what communication skills they believe engineers need. We analyzed the qualitative data to identify trends across all three universities by coding responses to see the themes that emerged.

Across the three universities, some students mention they wanted to improve their writing, but most feel more confident in the strength of their written communication than in their oral presentation skills. Interestingly, students report one of their greatest strengths in communication is their ability to listen. In responding to the open-ended questions about areas of growth, students at all three universities note they wanted to develop confidence in public speaking. For example, one student stated, "I want to be able to talk in front of different audiences without showing my discomfort" and another wrote, "I have a lot of nervous habits while speaking. Though I feel comfortable, I will make long pauses or pace a lot." Students also note they wanted to learn to avoid fillers (such as umm) in the qualitative responses, and they want to be more assertive in sharing ideas. One student wrote, for example, "in working in groups, I tend to get lost in the background" and another that, "I would like to improve the way that I communicate with my team members in a group setting. I often don't communicate my ideas or worries clearly or effectively which can add stress to a stressful situation when a problem arises."

The students across all three universities identified the many communication skills they felt engineers needed, including: 1) being concise, 2) tailoring the engineering message to diverse 
audiences, 3) communicating concepts to audiences with various levels of engineering and technical backgrounds, 4) simplifying complex ideas, and 5) working in a team. For example, one student wrote, "If we come up with a new product or idea that could be crucial to society, we need to be able to present it, make a display, write papers, etc. in order to allow more people to know about it ...." Another said, "I think that engineers should be able to explain concepts to audiences with varying backgrounds and levels of expertise." The ability to communicate in a team resonated with students at all of the universities as one of the most important skills for an engineer to have. One student reported that "cooperation as a team is the most important skill because it lays the foundation of achieving an objective and making progress in our field; it is what starts the ball rolling and is the first step in a chain of communication in the whole execution of a project." Another student mentioned that "the majority of engineering work happens in a group setting, so the members must be capable of accessing and improving an idea in a constructive and cooperative way."

An interesting preliminary finding comes from comparing the U.S. university to the two in Asia; this may provide insights into cross-cultural aspects of communication development that instructors can help students master. We did note a discrepancy in the quantitative and qualitative results in U.S. students' perspectives on listening skills. For example, although the survey results indicate they report they are confident in their ability to listen to team members respectfully, in the open-ended comments some of the U.S. students indicated they wanted to learn to be better listeners without dominating the conversation. Whereas students indicated their high confidence on the Likert scale in being a respectful listener, conversely they described weaknesses in listening skills in their qualitative responses. For example, a U.S. student stated, "I'd like to learn to lead without dominating others"; another shared, "I sometimes dominate a conversation without noticing"; and a third wrote, "I need more self-control so that I don't dominate conversations." Talking too much is an observation that many of the U.S. students made. More commonly, the students from the Asian universities indicated that listening respectfully and wanting to hear others' ideas were key parts of their communication styles. This quote reflects what many other Asian-based students wrote, "I am a very observant person and I don't speak unless I am certain of what I am saying. I don't interrupt others while they are talking and wait for others to finish sharing their ideas before interjecting my own."

\section{Discussion}

One of the benefits of conducting this pilot survey is to use the analysis as a springboard to develop topics for our focus group, guidelines for our course observations, and standards for our curriculum review. By conducting a preliminary analysis of the skills that students reported as being the most and least confident in, we can begin to identify patterns that will guide the full study.

For example, when we placed the consistently highest and lowest means for sub-skills on our mechanical-strategy/critical continuum, we saw that students across the three universities feel confident in the mechanics of writing (i.e., punctuation and grammar), but not in the comparatively foundational skills of presenting such as speaking without fillers and gesturing. Does this reflect the fact that more emphasis is put on writing than presenting in secondary schools in both cultures? Or, is there something about the immediacy of speaking that 
undermines students' confidence in their ability to do it? Is there more ego or face to protect if you are making a presentation as opposed to handing in a written assignment? If any of these conjectures are true (and we hope more data will help us determine if they are), how should that inform communication instruction?

We were surprised by the consistency in the finding that across all three universities students are fairly confident they can marshal evidence to support a main idea, argument, or recommendation in either a presentation or a piece of writing. Anecdotally, the communication instructors we know are not as convinced as the students are. We imagine there are several disparities in students' level of confidence and their actual performance abilities, and we wonder how those differences should inform the teaching of communication as well.

As we continue our more comprehensive study, we hope to include in the analysis the correlations, if any, between communication skills and curricular approaches. We also will explore the differences, if any, between communication skills in students from the two different cultures, broadly speaking. As we have the opportunity to continue the research and disaggregate data, we may be able to identify cultural aspects that impact self-efficacy in different areas of communication, including ways that students interact in teams. We also hope to be able to identify more precisely how students develop communication competencies as they move from first-year students to seniors. We noted above that students at all three universities felt very confident in their ability both to listen to team members' ideas and points of views and to provide feedback respectfully. Does that ability become more nuanced and refined as students move through their university experience_- perhaps along the lines William Perry [17] has described for other areas of students' cognitive and emotional growth?

From the qualitative results, it is clear that students perceive all four communication competencies are important for engineers to have. There is overlap in the data in that some of the most frequent skills that students identified as areas for growth are also indicated as important abilities for engineers to hone, as, for example, the ability to clearly and concisely convey technical information to people who do not have an engineering background. This aligns with the goal of The Engineer of 2020 and is important to consider in curriculum development in engineering. Similarly, the key areas that students feel least confident in can be considered opportunities to help them learn. For example, we found the students do not feel confident in identifying the audience for whom they are writing, expressing ideas clearly to others, clarifying the source of problems on teams when they arise, identifying verbal and non-verbal behaviors that may be due to cultural norms, and creating visuals that communicate concepts, narratives, or arguments.

Communication instructors, we hope, can benefit from our study by developing learning experiences that will improve self-efficacy in these areas. For example, when students are either working individually or in a team, the instructor can challenge them to communicate the solution to engineering problem to a lay audience. Ideally, the learning experience would include explicit instruction in good practice, scaffolding to support progress from beginning skills to more advanced ones, meaningful feedback, and opportunities for reflection. 


\section{Conclusion}

Engineering education across all types of curricular approaches must provide students with more than deep technical and analytical skills to meet society's complex challenges. Engineers need to communicate effectively across cultures and situations to design viable, feasible, and desirable solutions to today's problems. This research provides insight into current educational practices that are addressing the goals in seminal reports like The Engineer of 2020 [2]. It provides an opportunity for engineering faculty across institutions and internationally to compare effective pedagogical practices that will lead to strengthening the communication skills of future engineers $[3-6,15-16]$.

Bibliography:

[1] ABET Engineering Accreditation Commission. (2005). Criteria for accrediting engineering programs. Baltimore, MD: ABET, Inc.

[2] National Academy of Engineering. (2004-2005). The engineer of 2020: Visions of engineering in the new century. Washington, DC: The National Academies Press.

[3] Sageev, P. \& Romanowski, C. (2001). A message from recent graduates in the workplace: Results of a survey on technical communication skills. Journal of Engineering Education, 90(4), 685-693.

[4] Williams, J. (2002). The engineering portfolio: Communication, reflection, and student learning outcomes assessment. International Journal of Engineering Education, 18(2), 199-207.

[5] Bandura, A. (1977). Self-efficacy: towards a unifying theory of behavioral change. American Psychologist, 33, 344-358.

[6] Boiarsky, C. (2004). Teaching engineering students to communicate effectively: A metacognitive approach. International Journal of Engineering Education, 20 (2), 251-60.

[7] Organization for Economic Co-operation and Development (2005). Definition and Selection of Competencies (DeSeCo) Project. Retrieved from http://www.oecd.org/education/skills-beyond-school/41529556.pdf

[8] Gömleksi z, M. N. (2007). Effectiveness of cooperative learning (jigsaw II) method in teaching English as a foreign language to engineering students (Case of Firat University, Turkey). European journal of engineering education, 32(5), 613-625.

[9] Paretti, Marie C., and Christine B. Burgoyne. (2005). Integrating engineering and communication: A study of capstone design courses. In Web proceedings, ASEE/IEEE Frontiers in Education Conference. Retrieved from http://fie.engrng.pitt.edu/fie2005/papers/1205.pdf, pp. F4D.23-F4D.28. L (February 8, 2014)

[10] Leander, K. \& Paul, P. (2004). Speaking and writing: How talk and text interact in situated practices. In C. Bazerman and P. Prior. Mahwah [Eds.] What writing does and how it does it: An introduction to analyzing texts and textual practices. NJ: Lawrence Erlbaum.

[11] Bandura, A. (1986). Social foundations of thought and action. Englewood Cliffs, NJ, 1986.

[12] Bandura, A. (2006). Guide for constructing self-efficacy measures. In F. Pajares \& T. Urdan [Eds.] Self-Efficacy beliefs of adolescents. Charlotte, NC: Information Age Publishing.

[13] Kear, M. (2000). Concept analysis of self-efficacy. Graduate Research in Nursing, available at: $\mathrm{http} / /$ graduateresearch.com/Kear.htm

[14] Ausubel, D. (1960). The use of advanced organizers in the learning and retention of meaningful verbal material. Journal of Educational Psychology, 51(5), 267-272.

[15] Davis, D. C., Beyerlein, S. W., \& Davis, I. T. (2005, June). Development and use of an engineer profile. In Proceedings of the 2005 American Society for Engineering Education Annual Conference \& Exposition.

[16] Kaewpet, C., \& Sukamolson, S. (2011). A sociolinguistic approach to oral and written communication for engineering students. Asian Social Science, 7(10), p. 183.

[17] Perry, W.G. (1999). Forms of intellectual and ethical development in the college years. San Francisco, CA: Jossey-Bass. 